\title{
Sulama/İlaçlama Robotu için Nesne Tanıma Çalışmaları
}

\author{
Haluk Özgen ${ }^{*}$, Metin Turan ${ }^{2}$ \\ ${ }^{1}$ İstanbul Ticaret Üniversitesi, Mühendislik Fakültesi, Bilgisayar Mühendisliği Bölümü, İstanbul, Türkiye (ORCID: 0000-0003-3645-8761) \\ 2 İstanbul Ticaret Üniversitesi, Mühendislik Fakültesi, Bilgisayar Mühendisliği Bölümü, İstanbul, Türkiye (ORCID: 0000-0002-1941-6693)
}

(Bu yayın 26-27 Haziran 2020 tarihinde HORA-2020 kongresinde sözlü olarak sunulmuştur.)

(DOI: 10.31590/ejosat.779052)

ATIF/REFERENCE: Özgen, H. \& Turan M. (2020). Sulama/Illaçlama Robotu için Nesne Tanıma Çalışmaları. Avrupa Bilim ve Teknoloji Dergisi, (Special Issue), 50-58.

$\ddot{O} \mathbf{z}$

Yapay zekâ ve buna bağlı alt çalışma konularındaki bilimsel yöntemler, neredeyse her alanda yaygın biçimde kullanılmaktadır. Özellikle savunma sanayi ve tarım bu alanların en cazip uygulama merkezlerini olusşurmaktadırlar. Tarımda veya bahçelerde kullanılmak üzere daha önce geliştirmiş olduğumuz sulama ve ilaçlama prototip mobil robotumuzun, nesne (ağaç veya değil) tanıma kısmında yeterli düzeyde başarılı neticeler alınamamıştı. Bu çalışmada, bu mobil robot ile gerçek zamanlı görüntüler üzerinde karmaşık (asimetrik) yapıya sahip bitki nesnelerinin tanınması ve bu tanınma sonucuna göre ilaçlama mekanizmasının tetiklenmesinin başarımını artırılmıştı. Bitki nesnelerinin tanınması amacı ile Viola-Jones nesne tanıma algoritması kullanılmıştır. Bu algoritma ile yapılan eğitim ve parametrik düzenlemeler sonucunda elde edilen modelin 5 farklı senaryo yolu üzerinde sinanması sonucunda, mobil sulama/ilaçlama robotunun görme yetisi ve bitki nesnelerini tanıma başarııının yaklaşık olarak \%96.5 gibi oldukça yüksek bir düzeye çıkarıldığı görülmüştür. Ayrıca, ihtiyaç dolayısı ile uygulanan, herhangi bir nesneye ait görüntü eğitim setinin oluşturulmasına yönelik hızlı ve kolay bir yöntemin detayları makalede açıklanmıştır.

Anahtar Kelimeler: Mobil robotlar, nesne tanıma, görüntü seti oluşturma, yapay zeka, akıllı sistemler

\section{Object Recognition Studies for Irrigation/Medication Robot}

\begin{abstract}
Scientific methods in artificial intelligence and related sub-studies are widely used in almost every field. Defense industry and agriculture are the most attractive application areas of these fields. Sufficient successful results could not be obtained in the object (tree or not) recognition part of our irrigation and spraying prototype mobile robot, which we developed earlier for use in agriculture or gardens. In this study, with this mobile robot, the performance of the identification of complex (asymmetric) plant objects on realtime images and the triggering of the spraying mechanism according to this recognition result has been increased. Viola-Jones object capture algorithm was used to identify plant objects. As a result of the testing the model obtained through the training and parametric arrangements made to this algorithm on 5 different scenario paths, it has been observed that the success of recognizing plant objects and vision ability of the mobile irrigation/medication robot has been increased to a very high level of approximately $96,5 \%$. In addition, the details of a quick and easy method for creating an image training set for any object that is applied due to need are explained in the article.
\end{abstract}

Keywords: Mobile robots, object detection, creating image set, artifical intelligence, smart systems.

\section{Giriş}

Şüphesiz ki, nesne tanıma algoritmalarının en popüler olanı yapay sinir ağları olmakla birlikte, beraberinde bir takım uygulanabilirlik problemlerini de getirmektedir. Birçok alanda ve farklı veriler üzerinde büyük doğruluk oranlarına sahip olsa da, yapısal mantığı ve çok katmanlı mimarisi ile büyük sistem kaynaklarına ihtiyaç duymaktadır. Ancak mobil sistemler bazında düşünüldüğünde, bu durum ciddi performans problemlerine neden olmaktadır. Hızlı ve pahalı sistemler için iyi bir çözüm yolu olmasına rağmen, daha küçük sistem kaynaklarına sahip sistemlerde uygulanması zordur. Çünkü elektronik alt yapının zayıf olduğu 
sistemlerde, verilerin yavaş işlenmesinden kaynaklı, gecikmeli sonuçlar elde edilmektedir. Uygulanan yere ve zamana göre memnuniyet faktörü değişebilir ancak her durumda hızlı analiz avantaj sağlamaktadır. Özellikle görüntü işleme ve nesne yakalama gibi büyük iş gücü gerektiren uygulamalarda güçlü sistemlerin kullanılması kaçınılmazdır. Güçlü sistemler büyük maliyetler getireceğinden sistem tasarımları büyük önem taşımaktadır.

Çalışma kapsamında görüntü işleme yöntemi olarak, yapay sinir ağı algoritmaları yerine Viola-Jones (VJ) nesne tanıma algoritması kullanılmıştır. VJ algoritması, yapay sinir ağlarının aksine daha az işlem gücü ve sistem kaynağına ihtiyaç duyar. Buna bir gösterge olarak, kayan noktalı sayılar yerine tam sayılar üzerinde işlemler yapması verilebilir. Bilineceği üzere işlemci için tam sayıların toplanması ve çıkartılması çok hızlı gerçekleşir. Gerçek zamanlı uygulamada VJ nesne tanıma algoritması ile yüksek doğrulukta sonuçlara ulaşılabilir. Algoritmanın ana teması daha çok yüz tanıma üzerine kurulmuş olsada, sonraki yıllarda yapılan farklı araştırmalar bu algoritmanın birçok farklı nesne üzerindeki başarısını ortaya koymuştur. Örneğin, Liu Yun ve Zhang Peng yapmış olduklar çalışmada [1], VJ metodunu SVMs ile harmanlayarak insan eli ve onun farklı durumlarını gerçek zamanlı olarak tanıyabilen sistem geliş̧irmişlerdir. Bu çalışmaya göre, ağ üzerinde bulunan bir veya daha fazla bilgisayarın uzaktan kontrol (remote control) edilebilmesi sağlanmıştır. İnsan elinin farklı hareketlerine yönelik bilgisayarın açılması veya kapatılması tetiklenmektedir.

Bir farkı bakış açısı ile Ramana Isukapalli ve ekibi çalışmalarında [2], VJ nesne tanıma algoritmasına ek olarak kendi geliştirmiş oldukları çok sınıflı algılama algoritmasını (multi-class detection algorithm) uygulayarak, ilgili nesnelerin tanınmasındaki performans ve doğruluk değerlerini göstermişlerdir. Bu çalışmada vurgulanması gereken önemli kısım, tek bir görüntü içinde barınan farklı türlerdeki nesnelerin tanınması ve etiketlendirilmesidir. Bilindiği üzere aynı ekosisteme dahil olmayan nesnelerin oluşturduğu veri kümesi, VJ nesne tanıma algoritmasının standart sapmasını artıracağından mantıklı bir yaklaşım olmamaktadır. Çalışmada kullanılan otomobil, motosiklet, yapraklar ve insan yüzleridir. Bu dört sınıfa ait oluşturulan tek bir veri kümesi ile elde edilen sonuç lar VJ nesne tanıma algoritmasının doğruluk değerini düşürecektir. Ancak her bir nesnenin oluşturduğu veri kümeleri için elde edilen sınıflandırıcı ile gerçek zamanlı tanıma işlemi performans kayıplarına yol açacaktır. Yapılan çalışmada bu probleme ilişskin çözüm algoritması ve doğruluk değerine ilişkin yapılan test sonuçları deneysel olarak verilmiştir.

VJ nesne tanıma algoritmasının farklı bir veri kümesi üzerinde uygulaması olan Mohammad Mahdi Moghimi ve arkadaşlarının geliştirdikleri çalışma [3], taşıtların karayolları üzerindeki izleme kameralarından yakalanması üzerinedir. VJ nesne tanıma algoritmasına eğitim seti olarak sunulan pozitif görseller taşıtların ön yüzeylerinden belli aę̧larda çekilen fotoğraflardan sağlanmıştır. Belli bir simetri ve benzerliğe sahip taşıtların bu alandaki kullanılabilirliğini çarpıcı olarak göstermişlerdir. Önerilen algoritma ile taşıtların hem ön hem arka yüzeylerinden elde edilen veri setlerinden, çok sınıflı algılama algoritması kullanılarak tek bir izleme kamerası ile iki yönlü akışı kontrol edebilen taşıt tanıma algoritması gelisstirilebileceğinden bahsedilmiştir. Çalışmada, farklı 1şık şiddeti şartları alında elde edilen bulgulara ve bunlara ilişkin sonuçlara deginillmiştir. Aynı veri setleri üzerinde uyguladıkları farklı algoritmaların sonuçlarını ve ilişkilerini sunmaktadır. VJ nesne tanıma algoritmasını miras alarak yaptıkları uygulamada elde edilen doğruluk değeri çarpıcı biçimde yüksektir. Farklı ışık şiddeti oranları ve kalitelerde alınan videolar üzerindeki doğruluk değerlerinin \%94' e kadar artırıldığı belirtilmiştir.

Bir dizüstü veya masaüstü bilgisayar için VJ nesne tanıma süreci çok kısa süreler içerisinde gerçekleştirilebilirken, gömülü sistemler için büyük bir performans sorunu haline gelebilir. Bu bağlamda yapılan bir çalışma, Moad. Benkiniouar ve Mohamed Benmohammed tarafindan yayınlanmıştır [4]. Düşük güç tüketimine ve düşük performansa sahip sistemlerde VJ nesne tanıma algoritması esas alınarak bir optimizasyon algoritması tasarlamışlardır. Yayınlarında dile getirilen; performans kayıpları gelişen elektronik tabanlı çevrebirimleri sayesinde giderilecektir. Ancak ufak ölçekli sistemlerde halen uygulanabilirliği yetersiz kalmaktadır. Algoritmanın eğitim aşamaları, eğitimin yapıldıı̆ı sistemler ve modeller ve elde edilen sonuçlar detaylı bir şekilde değerlendirilmiştir.

Birçok görüntü işleme probleminde olduğu gỉbi, yüksek başarı oranının yanı sıra bir miktarda yanlış değerlendirme oranı vardır. Kullanılan alana ve bölgeye göre farklılıklar göstermekle birlikte, başarı oranları belli bir ölçüde memnuniyet sağlamaktadır. Yasaman Heydarzadeh, Abolfazl Toroghi Haghighat ve Nazila Fazeli çalışmaları sonucunda geliştirmiş oldukları modelin [5], VJ nesne tanıma algoritmasına göre dört kata kadar daha hızlı olduğunu ve doğru-yanlış oranını \%10'dan, \%2.4' lere kadar düşürdüğünü belirtmişlerdir. Ayrıca insan yüzünü içeren fotoğraflarda yüze ait olan içeriklerin tanınmasına yönelik bir çalışma sunulmuştur. Bilindiği üzere $V J$ nesne tanıma algoritmasının asıl hedef noktası insan yüzü tespitine yöneliktir. Bu çalışma VJ nesne tanıma algoritmașını temel almış ve yine insan yüzü tanıma üzerine bir çalışma olmuştur.

Rapee Krerngkamjornkit ve Milan Simic 2013 yılında yapmış oldukları çalışmada [6], VJ nesne tanıma algoritması kullanarak, video verisi üzerinde gerçek zamanlı insan vücudu tanıma algoritması geliştirmişlerdir. Makalelerinde, insan vücudunun gerçek zamanlı sistemlerinde kullanılan algoritmaların performans ve maliyetlerinden bahsetmişlerdir. Bu nedenle performans kayıplarına çözüm olarak çalışmalarında VJ nesne tanıma algoritmasını miras almışlar ve video verisi üzerinde etkin rol üstlendiğini vurgulamışlardır.

Dewiani Djamaluddin ve arkadaşları trafik yoğunluğunu ölçebilmek için VJ nesne tanıma algoritmasından faydalanmışlardır [7]. Özellikle benzer ve simetrik içeriklere sahip taşıtların ön kısımlarından alınan az sayıdaki örnek fotoğraflar ile \%92 başarılı tespit oranına erişilmiştir.

Birçok çalışmada belirtildiği üzere, makine öğrenmesinin ve nesne tanıma metotlarının renk, ışık şiddeti, şeklin karmaşıklı̆̆ gibi faktörlerden etkilenebileceği belirtilmiştir. Bu durum, VJ nesne tanıma algoritması için de geçerlidir. Yongzheng Xu ve diğerleri ilgili nesnelerin tanınmasında, nesnelerin görüntü düzleminde farklı rotasyonlarda bulunması ya da eğitim verisine göre farklı yönlerde görsellerinin elde edilmesinin, tanıma oranını büyük ölçüde düşüreceğini bildirmişlerdir [8]. Ancak VJ nesne tanıma algoritmasının orijinaline sadık kalarak bu problemin çözülebilir olduğunu vurgulamışlardır. Ayrıca insansız hava aracı (UAV) üzerinde otoyol trafik kontrolü ve taşıt yoğunluğunun tespitine yönelik çalışmalarında, havadan aldıkları görüntülerde açı değişiminden dolayı kaynaklanan 
doğruluk kayıplarını ele almışlardır. VJ nesne tanıma algoritmasında nesnelerin düzlemdeki yönelimlerindeki değişiminin getirdiği negatif sonuçlar, bir ek algoritma (yön düzenleme metodu) ile giderilmiştir.

$\mathrm{Bu}$ alanların dışında ilginç bir uygulama olarak toplumsal gelişimi olumsuz etkileyen pornografik görsellerin henüz görüntülenmeden önce tespit edilip soldurulması veya sansürlenmesi örneği verilebilir. Özellikle toplumun genç bireylerinin gelişimini ve yönelimlerini olumsuz etkilemekte olan pornografik içeriklerin engellenmesine yönelik güzel bir çalışma örneği Muhammad R Wiratama ve arkadaşları tarafından gerçekleştirilmiştir [9]. Gelişen internet ağı ve hızlanarak artan görsel içerik sayısının içinde barındırdığı olumsuz örneklerin giderilmesi veya önceden önlenmesi için farklı rrklara mensup insanlardan alınan cinsiyet belirleyici örnekler VJ nesne tanıma algoritması yardımıyla eğitilip, sınıflandırıcı elde edilmiştir. Ayrıca ten dedektörü algoritması (Skin Detector) yardımı ile odak noktaların renk uzayını daha net hale getirerek algoritmanın doğruluk performansı artırılmıştır.

VJ nesne tanıma algoritması kullanılarak, insan yüzü üzerinde ifade ve duygu tespiti de çalışılmıştır. Kartika Candra Kirana, Slamet Wibawanto ve Heru Wahyu Herwanto makalelerinde [10] VJ nesne tanıma algoritmasının gerçek zamanlı uygulamalarda hızlı ve yüksek seviyelerde doğruluk değerine sahip olduğunu belirtmişlerdir. VJ nesne tanıma algoritmasını, insan yüzündeki ifade belirten özelliklerle eğitmişlerdir. Ek olarak daha önce yaptıkları benzer çalışmayı, VJ nesne tanıma algoritması ile karşılaştırmış ve fark edilir şekilde iyi sonuçlar aldıklarını vurgulamışlardır.

Ancak bazı durumlarda, VJ nesne tanıma algoritması olumsuz yönde etkilediğinden doğruluğu düşebilmektedir. VJ nesne tanıma algoritmasının en önemli kısmı olan Adaptive Boosting Algoritmasıdır. Bu algoritmaya sunulan itgili örneklerin düzgün seçilmiş olması, sınıflandırıcı oluşumunu birincil dereceden etkilemektedir. Düzgün ve belirgin içeriklerle beslenemeyen algoritmanın eğitilmesi önce sınıflandırıcıyı, sonra şelale (cascade) zincirini olumsuz yönde etkileyecektir. Pooya Tavallali1, Mehran Yazdi ve Mohammad Reza Khosravi makalelerinde, sunulan eğitim verilerinin verimsizliği ve tutarsızhı̆ı, VJ nesne tanıma algoritmasının negatif yönde sonuçlar doğuracağını belirtmişlerdir [11].

VJ nesne tanıma algoritması benzerliği fazla olan nesnelere ait eğitim setlerinde oldukça iyi performans ve doğruluk seviyelerine ulaşabilir. Ancak farklı görüntü ve karmaşık yapılarda doğruluğu düşmektedir Buna ek olarak eğitim verileri ve nesnelerinin belirgin olması performansı çok etkilemektedir. Benny Hardjono ve diğerleri, VJ nesne tanıma algoritmasının performans ve doğruluk değerlerini, farklı görüntü işleme algoritmaları yardımıyla ölçmüşlerdir [12]. Ayrıca derin öğrenme algoritması kullanarak (YOLO), VJ nesne tanıma algoritması ile karşılaştırmasını da yapmışlardır.

Gerçek zamanlı çalışmalarda hızlı tanıma işlemi önemli olduğu kadar, hata oranının da az olması büyük önem taşımaktadır. Yukarıda bahsi geçen çalışmalar, VJ nesne tanıma algoritmasının hem doğruluk değerleri hem de gerçek zamanlı uygulamalardaki performansını değerlendirilmiştir. Genel kanı VJ nesne-tanıma algoritmasının hızlı sonuçlar verebildiği yönündedir. Ancak doğruluk değeri bakımından oran yüksek olmakla birlikte hata oranı da küçümsenecek kadar düşük değildir. Yüz tanıma üzerine, VJ nesne tanıma algoritmasına dayalı ve doğruluğun artırılmasına yönelik bir çalıșma Lu Wen-yao ve Yang Ming [13] tarafindan yapılmıştır. Makalelerinde, ilgili nesnelerin tanınması esnasında, kameranın görüntü aldığı açı ile ilgili nesnelerin arasına giren katı yapılı nesnelerin, nesne tanınmasındaki doğruluğu büyük ölçüde azalttığmı belirtmişlerdir. Makalelerinde yüz nesnesi ele alındığından, bir kupa veya Çin toplumuna has yemek çubuklarının insan yüzünün önüne geçtiği anda VJ nesne tanıma algoritmasının doğruluğunu büyük ölçüde düşürdüğünü deneysel gözlemlere dayalı olarak bildirmişlerdir. Ancak, VJ nesne tanıma algoritmasının başka algoritmalar ile kombine edilebilir olması onun bu zafiyetini ortadan kaldırmaktadır. Orijinal VJ nesne tanıma algoritmasının ve bu algoritmaya pekiştirici bir yaklaşımla geliștirdikleri algoritmanın karşılaştımasını yapmışlardır. Composite Feature yaklaşımı ile VJ nesne tanıma algoritmasının doğuluğı artırlmıștır.

\section{Viole Jones Algoritmasının Analizi ve Belirgin Özellikleri}

Eğitim aşamasını ofuşsuran verı seti örneklerinin belirgin ve kaliteli olması, ilgili nesnelerden alınan örneklerin aynı tür aileden olması, eğer nesneler karmaşık türden ise örneklerinin sıkıştııılmaması nesne tanıma algoritmasının doğruluğunu pozitif yönde etkileyecektir. Çünkü tutarsız şekilde alınan her örnek zayıf sınıflandırıcı seti oluşturulmasında sapmalara neden olacaktır. Sıkıştırılan örnek görsellerinde meydana gelen kayıplardan dolayı ilgili nesnenin içeriklerinin kaybolmasına sebebiyet verecektir. İlgilenilen nesnenin cinsine göre içeriklerin önemi farklılık gösterebilir. Detaylar önemli içerikleri temsil ediyorsa, sıkıştırma işlemi eğitimi olumsuz yönde etkilemektedir. Ayrıca sıkıştııılan nesne örnekleri sıkıştırılırken aynı orantılarda olacak şekilde sıkıştırılmalıdır. Orantısız sıkıştırmalar zayıf sınıflandırıcı seçilmesi esnasında standart sapmayı artıracaktır. Tanınması istenen nesneden elde edilen ilgili örüntüler eğitim aşamasında sunulduğunda $24 \times 24$ piksel için 160 bin civarında Haar-Like içerikleri sunulur. Haar-Like içeriklerinin seçilmesi ve VJ nesne tanıma çerçevelerinin oluşturulması Adaptive Boosting algoritması sayesinde gerçekleştirilir. Nesnelerden alınan 50x50 piksellik örnekler 24×24 piksellik vektör formatına dönüştürüldüğünde kayıplar meydana gelir. Bu nedenle nesneden alınan örüntünün bileşenleri önem arz ediyor ise sıkıştıılmadan eğitime sunulması gerekir. Ayrıca nesneden alınan örneklerin boyutsal oranları sabit olursa her örnek için daha etkin eğitim koşulu sağlanır. Örnek verilirse, her bir nesneden alınan örneklerin kare özelliği taşırsa, vektör formata dönüştürülürken kare özelliği korunacak ve ölçeklendirmeden doğan içerik sıkıştırması olmayacaktır. Bu sayede belirlenen 24×24 piksellik vektör çerçevesi aslında kayan VJ nesne tanıma çerçevelerinin boyutunu belirlemiş olur.

VJ nesne tanıma çerçevesi, kendini oluşturan birçok sabit konumlu zayıf sınıflandıııcı adı verilen dikdörtgen yapılı içeriklerden oluşur. Bu zayıf sınıflandırıcılar, Adaptive Boosting Algoritması tarafından en uygun olanlarının seçilmesiyle nesne tanıma çerçevesi oluşturulur. Zayıf sınıflandırıcıların her biri belli bir konumda bulunduğundan dolayı, nesne tanıma esnasında nesnenin açısal değişimleri VJ nesne tanıma çerçeveleri tarafından reddedilecektir. VJ nesne tanıma algoritmasının eğitimi sonucunda bir dizi VJ 
nesne tanıma çerçeveleri oluşturulur. Bu şekilde şelale sınıflandıııcı adı verilen birden fazla çerçeve ile güçlü sınıflandırıcı zinciri kurulur ve güçlü bir filtreleme mekanizması sağlanır. Her bir VJ nesne tanıma çerçevesi belli miktarda zayıf sınıflandırıcı barındırdığından şelale sınıflandırıcıyı oluşturan toplam zayıf sınıflandırıcı sayısı da çok fazla olmamaktadır. Bu süreç bir nesneyi sınıflandırmak için esasen lineer bir filtre görevi görür. Az sayıda zayıf sınıflandırıcı ile etkin filtreleme ve hız kazancı sağlanır. Süreç Haar-Like içeriklerinin sunulması, integral resmi, Adaptive Boostin algoritması ve Cascade sınıflandırıcı şeklinde gerçekleşir [14].

$\mathrm{Bu}$ çalışmada, daha önce geliştirmiş olduğumuz Kamera Destekli Mobil İlaçlama ve Sulama Robotu [15] üzerinde birkaç modül değişikliği yapılarak performans ve tutarlı hareket edebilme yeteneği artırılmıştır. Önceki tasarıma göre daha doğrusal hareket sağlanmış ve boyutu artırılmıştır. Nesne tanıma algoritması olarak VJ uygulanmış, bu algoritmanın eğitiminde kullanılmak üzere mobil bir mekanizma geliştirilerek, farklı açılardan görüntü alınarak eğitim kümesi oluşturulmuştur. Güncellenen mobil robot yapısı ve VJ nesne tanıma algoritması ile daha yüksek oranlarda başarım elde edilmiştir.

Makalenin bundan sonraki kısımlarında, Bölüm 3' de resim örneklerinin toplanması, mekanizması ve işlenmesi, Bölüm 4'te VJ nesne tanıma algoritmasının eğitimi, Bölüm 5' de sistemin sınanması ve Bölüm 6'da sonuçlar paylaşılmıştır.

\section{Nesne Örneklerinin Toplanması}

\section{1. Örnek Toplama Mekanizması}

Çalışmada, bitki veya ağaç nesnelerinden örnekler farklı bir yöntemle elde edilmiştir. Bu yöntem, gelenekșel olarak kullanılan yaklaşımlara göre çok daha verimli ve kolaydır. Web üzerinden örnek toplamak, ya da hali hazırda var olan veri kümeleri ile çalışmak özel senaryonun oluşturulmasını kısıtlayabilir. Bitki ve ağaç örneklerini içeren fotoğraflarm tek tek toplanarak, ilgili kısımlarının çıkarılması ve pozitif örnek olarak VJ algoritmasına sunulması zaman alıcı bir çalışmadır. Ayrıca mümkün olduğunca temiz, kolay ve hızlı örnekler alınması önem taşımaktadır. Örneklerin kalitesi, eğitim aşamasının başarısını etkileyen ve modelin doğruluğunu belirleyen en önemli faktördür. Elde edilen örneklerin sadece ilgili nesnenin parçasını içermesi, eğitim aşamasının çok daha verimli olarak uygulanmasını sağlayacaktır. Bu sebeplerden dolayı, düşük hızda ve yatay eksende dönen bir levha ya da plakanın üzerine yerleştirilen maketlerin, belli bir zaman dilimi ve miktarda örneğinin alınması uygulanmıştır. Dönen levha üzerine ilgili nesnenin kendisi veya ilgili nesnenin maketi yerleştirilerek üç boyutlu tarama mekanizmasının ön aşamasıs oluşturulur. Yavaş hızlarda dönen bu mekanizmanın karşısına sabit veya hareketli bir kamera konularak istenen mesafelerde, istenen açılarda ve farklı arka planlarda örneklerin hızlıca alınması mümkün kılınır. Genel anlamda bu yöntem kullanılarak, neredeyse her nesnenin maketi ile örneklerinin alınması sağlanabilir. Maketi olabilecek örnekler, otomobiller, ev ve binalar, elektronik cihazlar ve bileşenleri, beyaz eşyalar, meyveler hatta doğal ortamlarda bulunan her tür nesne olabilir. Bir nesnenin maketi oluşturularak hem yer tasarrufu hem de mali kazanç elde edilir. Bu yöntem ile ayrıca, karmaşık yapılı ve asimetrik objelerin her bir noktasından örnekler alınması mümkün olabilmektedir. Bir telefon nesnesi için 100 adet örnek alınarak eğitim algoritmasından iyi sonuçlar elde edilebilir. Aynı şekilde bir elma veya futbol topunda alınan az sayıda örnek ile model daha iyi eğitilebilir. Bununla birlikte, nesne karmaşıklığı arttıkça eğitim sonucu elde edilen başarı düşmektedir. Özellikle simetrik yapıya sahip objelerde başarı oranı gözle görülür şekilde artmakta, az sayıdaki örneklem eğitim için yeterli olmaktadır. Çalışmada kullanılan bitki nesnelerinin çok yapraklı ve asimetrik dağılımlara sahip olması nedeniyle alınan örnek sayısının da fazla olması gerekmektedir. Bu sebepten dolayı, örnek görüntüler dönen levha mekanizması kullanılarak farklı açılarda toplanmıştır. Sadece VJ nesne tanıma algoritması için değil, ayrıca yapay sinir ağı tabanlı model oluşturma çalışmalarında örnekletin toplanması kolaylaşır. Geliştirilen görüntü toplama hareketli levhası Şekil 1'de görülmektedir.

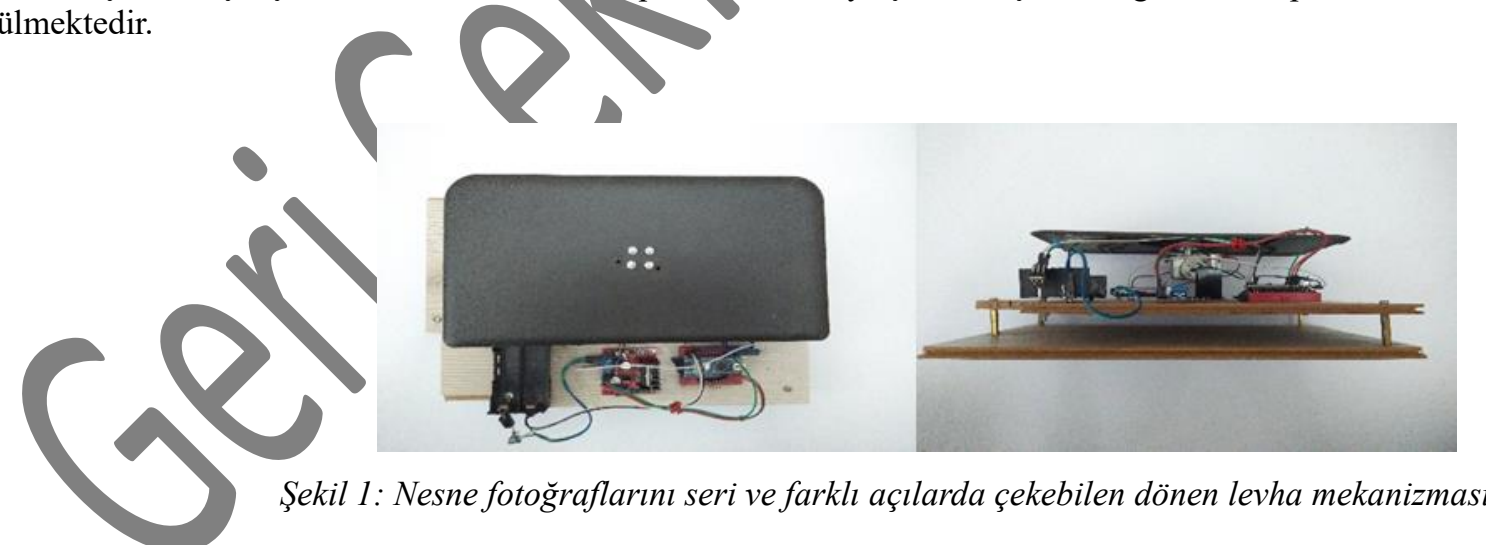

Yukarıda verilen dönen levha mekanizmasının alt konumunda bulunan suntaların eni ve boyu 20 santimetreye 30 santimetredir. Sunta levhaların kalınlığ 0,75 milimetredir. Aralayıcı somunlar yardımı ile iki katman haline getirilmiş ve belli bir ağırlığı sağlamasından dolayı iki adet kullanılmıştır. Suntalar belli yerlerden olmak kaydıyla dört aralayıcı somunla birbirinden ayrılmışlardır. Üstteki sunta levha DC motor, motor sürücü 18650 pil yuvası ve breadboard için zemin oluşturmuştur. Fotoğrafları çekilecek olan nesneler üstteki dönen levhaya yerleştirilir. Üst kısımda dönen levhanın boyutları 14 cm' ye 24 cm' dir. Dönen levha DC motor ile bağlantılı ve hız kontrolü Arduino Nano model bileşenlerle sağlanmıştır. Bu yöntem ile nesnelere ait görüntü serileri hızlıca elde edilebilmektedir.

Kullanılan elektronik alt yapıya bağlı olarak dakikalar içinde yüzlerce fotoğraf çekilebilir. Mobil robotun kamerası Raspberry Pi 3 uyumlu Raspberry Pi Camera Rev 1.3 model kamerası olduğundan çekilecek olan fotoğrafların kalitesi ve çözünürlüğü sınırlıdır. Hareketsiz nesnelerin fotoğraflarından elde edilen örneklerin kalitesi VJ nesne tanıma algoritması için yeterli seviyededir. Ancak 
yukarıda bahsedilmiş olan dönen levha mekanizması hareketli bir yapıya sahip olduğundan birtakım problemleri de beraberinde getirmektedir. Cisimlerin hareketi esnasında elde edilen fotoğrafların bazı bölgelerinde kaymalara ve bulanıklaşmalara neden olmaktadır. Daha gelişmiş kameralar ile hareket eden cisimlerin fotoğraflarının elde edilmesi daha kolay olacaktır. Düşük seviye tepkime ve tetikleme süresi ile hareket eden cisimlerin fotoğrafları net bir şekilde çekilebilir. Ancak çalışmada kullanılan kameranın hareketli fotoğrafları çekmesi ve kaliteli görüntüler yakalaması daha zordur. Bu sebeplerden dolayı bu levhanın çok daha yavaş açılarda, yani yavaş hızlarda dönmesi gerekmektedir. Düşük hızla dönen levha üzerindeki nesnelerin fotoğraflarının alınması bulanık görüntülerin belli bir oranda önüne geçmektedir.

\section{2. Örneklerin Toplanması}

Çalışmada kullanılan maket bitki nesneleri, yapay süs bitkilerinin parçalarından birleştirilerek elde edilmiştir. Bu parçalar esasen terrarium objeleridir. Küçük ebatlı terrarium bitkilerinin birleşimiyle yapay ağaçlar elde edilmiştir. Bu yapay objeler düz tahta çubuklara plastik kelepçeler yardımıyla monte edilmiştir. Düz tahta çubukların bu modeli taşıyabilmesi için en alt kısmına ek olarak silindirik kutular tutkallar yardımı ile yapıştıılmıştır. Bu sayede model dik olarak istenen konuma yerleştirilebilir hale getirilmiştir. Senaryo tekrar tekrar baştan kurulabilir veya farklı modeller elde edilebilir. Bu sayede, test aşamalarının istenen şekilde ayarlanmasına da olanak sağlamaktadır.

Yukarıda belirtilenler doğrultusunda üç adet bitki objesi elde edilmiştir. Bunlar farklı yapılı terrafium objelerinin birleşiminden elde edilmiştir. Bitki objelerinin fotoğrafları elde edilmeden önce ortam ışıklandırılmasına dikkat edilmesi gerekmektedir. Ayrıca dönen levha mekanizmasının bulunduğu arka planın temiz ve tek ton olması örneklerin çıkartılmasr esnasında kolaylık sağlamaktadır. Odanın ışıklandırması 6 Watt $6500 \mathrm{~K}$ beyaz led ambul ile sağlanmıştır. Işı̆̆ın dönen levha mekanizmasına olan uzaklığı yaklaşık 2 metre ve 1şı 40 derecelik bir açı ile aydınlatmaktadır. Aydınlatma keskinliğinin giderilmesi amacryła önûnde 1şık geçiren bir perde bulunmaktadır. Bu sayede gölge oluşması ve aşırı parlaklıklar engellenmiştir. Çünkü kuvvetli ve filtresiz aydınlatma ile elde edilen örneklerin eğitimi ile elde edilen sonuçlarda \%50 ye varan kayıplar gözlemlenmiştir. Aydınlatmanın buşsekilde yapılması sonucu, bitki nesnelerinin karmaşık yapısındaki her noktanın neredeyse eşit miktarlarda aydınlatılması sağlanmışır. Çok düşük ışıklandırma ve çok kuvvetli ışıklandırma yapılan ortamlarda alınan örnekler ile yapılan eğitimler yetersiz kalmıştır. Ancak eşit dağılımlı bir aydınlatma ile elde edilen örneklerin eğitimi ile elde edilen sonuçların çok daha iyi olduğu gözlemlenmiştir.

Dönen levha mekanizmasına yatayda ve dik açı ile olmak kaydıyla Raspberry Pi ve ona bağlı kamera yerleştirilmiştir. Kabaca 1,5 metre mesafede konumlandırılmıştır. Ek olarak dönen levha mekanizması arka plana, ya da diğer bir deyiş ile duvara tam bitişik değildir. Duvar ile mekanizma arasında yaklaşık olarak 15 santimetrelik bìr boşluk bulunmaktadır. Çekilecek fotoğrafların çözünürlüğü 1024x768 olarak ayarlanmıştır. Ancak bu elde edilen görüntüler daha sonra 640x480 çözünürlüğüne dönüştürülmüştür.

Levhayı döndürecek olan motorun dakikadaki tur sayısı kullanım kılavuzunda belirtildiği üzere 6' dır. Raspberry Pi 3 kamerasının peş peşe fotoğraf çekebilme hızı $[0,1]$ aralığında üretilen düzgün kayan ayrımlı sayının (uniform float number) saniyeye çevrilmesiyle ile belirlenmiştir. Bu sayede çekilen fotograflarda aynılıkların giderilmesi ve bitki nesnesinin her bir yüzeyinin eşit ve tam olarak taranması sağlanmıştır

Çalışmada, her bir bitki nesnesi için 10000 fotoğraf çekilmiştir. Her biri için harcanan süre ise, yaklaşık 3 saat 40 dakikadır. Görüldüğ̈ü gibi 30 bin tane örnek 11 saat gibi kisa bir sürede elde edilmiştir. Bu süre kullanılan elektronik alt yapıya ve belirlenen değerlere göre değişiklik gösterebilir ve azaltılabilir. Bu mantıktan yola çıkarak başka nesnelerin maketleri üzerinden de örnekler elde edilebilir. Gerçeğe uygun olarak modellenmıs bir maket arabanın örneklerinin alınması eğitim öncesi veri toplamada büyük kolaylık sağlayacaktır. Farklı açılardan bir bina modelinin maketinden yüzlerce hatta binlerce örnek elde edilebilir. Toplanacak olan örneklerin kolayca çoğaltılmasının yanısıra, çeşitliliğe de olanak tanıyacaktır.

\section{Viola-Jones Algoritmasının Eğitimi}

Elde edilen fotoğrafları daha sonra $640 \times 480$ piksel boyutlarında olmak şartıla, renk yapısı RGB' den gri tonlamaya dönüştürülmüştür. Bu dönüşüm sonucu resim kalitesinde bir miktar kayıp olmakla birlikte, ilgili nesneye ait detaylar korunmaktadır. Aşağıda bitki nessnesinin her iki durumdaki yapısını temsil eden örnek bir resim Şekil 2'de verilmiştir.
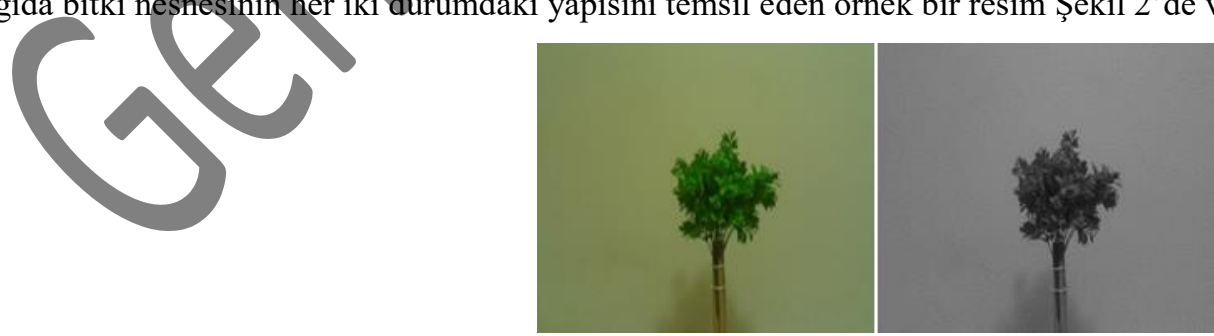

Şekil 2: Soldaki fotoğraf $1024 x 768$ piksel RGB, sağdaki fotoğraf 640x480 piksel çözünürlükte gri tona dönüştürülmüş hali.

Dönüşüm sonrası fotoğraftan ilgili nesneye ait özelliklerin çıkarılıp örneklendirilmesi gerekir. Örneklerin çıkarılmasında izlenecek yol arzu edilen her şekilde olabilir (Şekil 3). Fakat dikkat edilmesi gereken husus, bu nesneyi ayırt edilmesi beklenen diğer nesnelerden ayıran özellik bölgelerinin ön plana çıkartılmasıdır. Örneğin en basit yöntem, bitki objesinin tüm yapısını içerecek şekilde kırpılması olabilir. Veya sadece gövde üstünde kalan ve yaprakların sınır bölgelerine kadar olan kısım ya da sadece yapraklı alanın iç bölgesinden örüntüler alınabilir. Bununla birlikte, modelin dışından alınacak olan örüntülerin sınır bölgelerine dikkat edilmelidir. Parçaları eksik kalan nesneler eğitim sonrası tespit edilebilirliği olumsuz yönde etkilemektedir. Ek olarak alınan örneklerin bölgesellik 
yaklaşımı, eğitimin erken ya da geç bitmesine etkisi bulunmaktadır. Bitki nesnesi dışından alınan örneklerde çok erken turlarda bitmesine neden olmaktadır. Hatta yapılan eğitim denemelerinde henüz 2. turda iken sonlandığı gözlemlenmiştir. Ancak yapraklı bölgenin iç kısmından alınan örneklerle yapılan testlerde 12 tura kadar uzadığı gözlemlenmiştir. Bunun temel sebebi nesne dışındaki bölgenin taşıdığı bilgi az iken, ağaç yaprakları daha fazla bilgi içermektedir. Yapraklı bölgenin merkezinden alınan örneklerde tur bazında zayıf sınıflandırıcıların sayısı 50 tekrarı bulabilirken diğer durumlarda en fazla 10 tekrar olmuştur. Eğitimin başarısı için, açıklandığı üzere, bitkileri daha iyi temsil eden yapraklı kısmını oluşturan bölgelerin orta kısımları kullanılmışır.

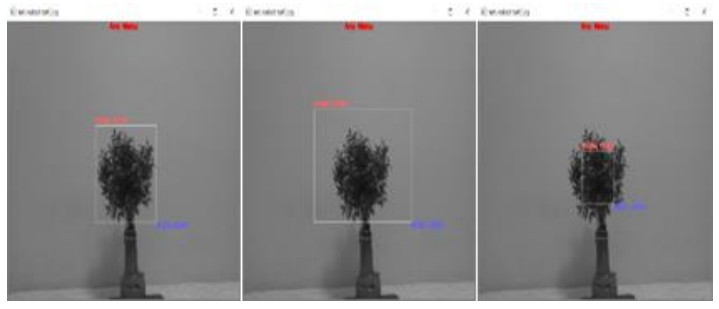

\section{Şekil 3: İlgili nesnenin sınır bölgesi, sınır bölgesi dışı ve yapraklı bölgenin iç yapısından temin edilen örnekler}

Bitki nesnesinin örneklerinin topluca alınması ilk belirlenen koordinatlara göre ilerleyecektir. Bunun dezavantajı, levhanın dönmesi esnasında dikeyde oluşan sağa ve sola kaymalardır. Çünkü modellerin üst bölgelerinde meydana gelen oynamalar toplu örneklerin alınması sırasında nesnenin belli bölgelerinin eksik ya da fazla alınmasına yol açacaktır. Görünüş̧te ufak kaymalar gibi görünseler de eğitimin sonucu etkileyecektir. Ayrıca, çalışmanın başarısı için alınan örneklerin en boy koordinatlarının da eşit olması gerekmektedir. Bunun başlıca nedeni, alınan örneklerin vektör formatına dönüştürülmesindendir. Eğer alınan örneklerin koordinatları eşit oranlarda vektöre çevrilmezlerse, içeriklerinde kayıplar meydana gelir. Örneğin, 100x80 piksel olarak kırpılan kısım vektör formuna çevrilirken oranlar korunmazsa, alınan örneklerin içerikleri orijinal yapılarındaki en boy oranını korumayacaktır. Bu sebeple çalışmada en boy oranı sabitlenerek örnekler alınmıştır. Vektör formuna çevirme $42 \times 42$ şeklinde gerçekleştirilmiştir. Bu şekilde içeriklerde aynı oranda değişime uğrayacağından dolayı eğitim esnasında sunulan Haar içerikleri de aynı oranlarda değişmektedir. Örneklerin asıl ölçeklerine sadık kalındığında daha iyi sonuçlar verdiği gôzlemlenmııştir.

Vektör formuna dönüştürülürken verilen değerin yüz tanıma (face detection) için kullanılan değerlere göre fazla olmasının sebebi ise asimetrik ve küçük yapıların daha belirgin olmasından dolayıdır. Bu şekilde oluşturulan her bir vektör için 1.500 .000 üzeri zayıf sınıflandırıcı adı verilen VJ Haar özelliği sunulur. Eğitim için kullanılan platform açık kaynak OpenCV versiyon 3,43` tür. OpenCV açık kaynak kütüphanesi kullanılarak örneklerin eğitımi sağlanmıștır. Eğitim için alınan örneklerden, sadece 1500 tanesi pozitif örnekler olarak sunulmuștur. Bu veri kümesi, her bir bitki nesnesinden 500 adet olmak suretiyle oluşturulmuştur. Pozitif örnek veri kümesinin yanında 3000 adet negatif örnek içeren ayrı bir veri kümesi de verilmiştir. Parametrelerden, minimum hit rate 0.999 ve false alarm rate 0,40 olarak belirlenmiştir Egitimde kullanılan donanım, işlemci modeli Intel i5-2430m ve ana belleği $8 \mathrm{gb}$ ram $1333 \mathrm{Mhz}$ olan bir diz üstü bilgisayardır. Veriler $32 \mathrm{gb}$ Usb flash bellekten okunmaktadır. İşlemci çoğunlukla tek çekirdek üzerinde turbo frekansta $2.95 \mathrm{GHz}$ hızında çalş̧mış̧ır. Bu koşullar altında eğitim 10. turda tamamlanmış ve geçen süre yaklaşık olarak 2 gün 20 saattir.

\section{Sistemin Sinanması}

Sınamalarda, birbirine bağımlı nesnelerin bulunduğu, birbirinden farklı nesnelerin olduğu ve sadece bir nesnenin bulunduğu olmak üzere farklı senaryolar uygulanarak, modelin öğrenme performansı ölçülmeye çalışılmıştır. Senaryonun gerçekleşeceği ortamın aydınlatma düzeyi standartlarda olmakla birlikte, 4 adet 6 Watt $6500 \mathrm{~K}$ renk sıcaklığına sahip LED ampul ile destek sağlanmıştır. Sınama ortamının yol užnluğu 3 metredir. Ayrıca odanın aydınlatılması saydam tül perdeler ile bir miktar kırılmıștır. Perdelerin sınama ortamının arka planını oluşturmasının yanısıra, arka planda bir miktar gürültü ve karmaşa oluşturmakta amaçlanmıştır. Bu sayede gürültü olmayan düz beyaz arka plan ile yapılacak sınamalara göre zorluk artırılmıştır. Ayrıca sınama nesneleri doğrudan güneş 1Şıllarını almamaktadır (Gerçek ortamda bu tür ışınların oluşturabileceği yan etkilerden korunmak üzere filtreleme yapılmalıdır). Mobil robotun sınamayı sarsıntı olmadan, doğrusal yapabilmesi için zemin düz ve sunta yapılıdır (gerçek ortamda sarsıntıya karş kamera görüntülerinin sabitlenmesi önem arz edecektir). Bu sayede mobil robotun ilerlemesi esnasında doğrusal sapmalarnn önüne geçilmiştir.

Sınama nesneleri, daha önce bahsedilen bitki nesneleri ve buna ek olarak kullanılan maket evlerdir. Maket evler, bitki nesnelerinin diğer varlıklardan ayırt edilebilirliğinin bir göstergesi olarak kullanılmıştır. Ev ve ağaçların sulanmasındaki doğruluk oranının yüksek olması birinci amaç olduğundan, her bir sınama aşamasında bunların farklı kombinasyonları denenmiştir. Maket evlerden birinin, yüzeylerinden birisi yeşil tonda bir renge boyanmıştır. Yeşile boyanmasındaki amaç VJ nesne tanıma algoritmasının renklere karşı direncinin ölçülmesine yöneliktir. Algoritma renkler üzerinde işlem yapmasa bile, aynı renklere sahip bölgeler aynı parlaklıklara sahiptir. Aynı parlaklıklara sahip bölgelerin iç içe geçmesinin bitki nesnesinin tanınmasında sağladığı etki anlaşılmaya çalışılmıştır. Diğer bir deyişle, bitki nesnelerinin yeşil tonlarını içeren yapraklı bölgesiyle, ev nesnesinin yeşile boyanan yüzeyinin farklılığının VJ algoritması tarafından ayırt edilebilme başarısı ölçülmüşsür.

Mobil robotun hareketi, kameranın saniyede bir görüntü alınması ve görüntünün analiz edilmesi ve 0,75 saniye kadar ilerlemek şeklinde gerçekleşmektedir. Bunun nedeni görüntülerin yeteri kadar hızlı işlenememesinden kaynaklıdır. Örneğin, saniyede 25 frame 
işlem yapılamadığından verimlilik oldukça düşük kalacaktır. Mobil robotun hareketi esnasında elde edilen görüntülerde kaymalar meydana geleceğinden doğru sonuçların elde edilmesi mümkün olmayacaktır. Ayrıca, kullanılan RaspberryPi 3 model B+ gömülü işlemcisi bu görüntüleri hızlı bir şekilde işleyemeyecek ve ağır iş yükü altında kalacağından isınma problemine yol açacaktır. Bu olumsuz durumlardan etkilenmemek için bir frame al, dur ve değerlendir, sula (veya sulama), sonra ilerle şeklinde bir yöntem ile sınamalar gerçekleştirilmiştir. İzlenen bu yöntem sayesinde, daha net fotoğraflar elde edilerek, daha doğru analizler yapılmıştır.

Mobil robotun kısa tutulan ilerleme süresi ile ilerlenen yolda daha fazla alanın taranmasını sağlanmaktadır. Başlangıçta mobil robot önce görüntü alır ve değerlendirmeyi yapar. Daha sonra değerlendirme durumuna göre çekilen görüntüde ilgili bitki nesnesii yakalanırsa sulama mekanizması tetiklenir. Sulama sonrası ilerleme sağlanır. İlerlemenin sağlanması için öncelikli olarak mobil robotun kızıl ötesi mesafe sensörlerinden gelen bilgiye göre değerlendirilmesi gerekmektedir. Mobil robotun ilerlenen yol üzerinde konumlandırılmış her iki yönü tarayan kızıl ötesi sensörlerinden bir engel bilgisi (yolun sonu anlamında kullanılmaktadır) gelmemiş ise ilerleme sağlanır. Her iki kızıl ötesinden de engel yakalandığı bilgisi gelirse mobil robot bekleme konumuna geçer. Bu bekleme konumu sınama aşamasında kullanılmamıştır. Eğer kızıl ötesi sensörlerden biri engel bilgisini alırsa ilerleme yönü tersine döner ve o yönde ilerleme bir sonraki engele kadar devam eder. Bu sayede 3 metrelik sınama yolu üzerinde birden fazla ilerleme sağlanarak, sınama aşamasında elde edilen sonuçların sayısı artırılmaktadır.

Sınama yolu bu şekilde otomatik olarak birkaç kez taranır. Sınama yolunun her iki ucunda bulunan engeller sayesinde tek seferlik çalışmada birden fazla yol taraması yapılması sağlanır. Örneğin sınama yolunun 5 kere taranması istenirse 15 metrélik bir sınama mesafesi elde edilecektir. Pinpon topunun iki duvar arasında sekmesi gibi, mobil robotta her iki engel arasında dönüşümlü olarak ilerleme sağlayacaktır.

Mobil robot kamerasının çektiği 640x480 çözünürlügündeki fotoğraflara filtre uygulanmıştır. Bu filttre 640 pikselin üç parçaya (segmentasyon) bölünmesiyle elde edilmiştir. Üçe bölündüğünde oluşan ortadaki bölüm görüntünün analizi için kullanılmış ve bu bölümün sağında ve solunda kalan kısımlarda ise nesne analizi yapılmamıştır. Böyle bir yöntemin kullanılmasının iki avantajı vardır. İlki, azalan piksel sayısı ile yapılan işlem üçte birine düşecektir. İkincisi, tanımanın yapılması mobil robotun bitki nesnesinin (veya ev) tam karşı doğrultusundayken gerçekleşmesine fayda sağlayacaktır. Bu sayede sulama mekanizması algılanan bitki nesnesini neredeyse tam ortadan sulayabilecektir.

\section{Sonuçlar}

Sınama, sadece bitki nesnelerini içeren yatay yol, sadece maket evleri içeren yatay yol, hem maket evleri hem de bitkileri içeren yol, her iki modeli yakın konumlarda içeren yatay yol ve her iki farklı modelin iç içe geçtiği yatay yol olmak üzere toplam beş farklı senaryo ile uygulanmıştır. Aşağıda verilen tablolarda Sembolü nesnenin bitki olarak tanındığını (pozitif sınıf), $\boldsymbol{X}$ sembolü ise nesnenin bitki olarak tanınmadığını (negatif sınıf) sembolize etmektedir. Senaryolarda kullanılan maket evlerden üçü aynı diğeri ise farklı modeldedir. Senaryolarda, aynı modelde olan maket evlèrden yüžeyi yeşil olanın yeşil yüzeyi mobil robotun kamerasının bulunduğu yöne dönük olarak konumlandırılmıștır.

Sadece bitkileri içeren ilk senaryo yolu, 3 metrelik yol üzerinde 4 adet bitki nesnesinin eşit aralıklarda yerleştirilmesiyle oluşturulmuş̧ur. Her bir bitki nesnesinin birbirine olan uzaklığı yaklaşık 75 santimetredir. Mobil robot yolun sol tarafindaki en uç noktada konumlandırılmıştır. Sınama başladığı anda, ilk görüntü alınır ve değerlendirilir. Daha önceden de bahsedildiği üzere 0,75 saniyelik düşük hızlardaki ilerlemeler sonráki görüntülerin alınması ve sınanmasını sağlar. Yol bitiminde mobil robot yön değiştirerek sınama işlemini tersten yapmaya başlar. Bahşi geçen senaryo yolu üç kere taranarak aşama sonlandırılmışıtır. Bitki nesneleri ile karşılaşma toplam $12 \mathrm{kez}$ sağlanmıştır. Her karşılaşmada, bitki nesnesi $\mathrm{VJ}$ eğitim modeli tarafından tam olarak tespit edilmiştir. Bu senaryonun başarısı \%100 olarak bulunmuştur. Mobil robotun senaryo yolunda bitki nesneleri tanımasına ilişkin tablo Tablo 1' de verilmiştir.

\begin{tabular}{|c|c|c|c|c|}
\hline Test-1 & Bitki-1 & Bitki -2 & Bitki -3 & Bitki -4 \\
\hline Soldan- & $\checkmark$ & $\checkmark$ & $\checkmark$ & $\checkmark$ \\
\hline Sağdan-Sola & $\checkmark$ & $\checkmark$ & $\checkmark$ & $\checkmark$ \\
\hline Soldan-Sağa & $\checkmark$ & $\checkmark$ & $\checkmark$ & $\checkmark$ \\
\hline
\end{tabular}

İkinci senaryoda ise sadece maket evler kullanılmıştır. Maket evlerin dizilimleri ilk senaryodaki gibidir ve kullanılan maket ev sayısı da benzer olarak 4 adettir. Senaryo yoluna yerleştirilen evler 3 metrelik uzunluğu eşit olarak bölecek biçimde 75 santimetre aralıklarda konumlandırılmışlardır. Sadece maket evleri içeren sınama yolu da benzer biçimde soldan başlanmak suretiyle 3 kez taranmıştır. Ev nesneleri ile karşılaşma toplam $12 \mathrm{kez} \mathrm{sağlanmıştır.} \mathrm{Her} \mathrm{karşılaşmada,} \mathrm{ev} \mathrm{nesnesi} \mathrm{VJ} \mathrm{eğitim} \mathrm{modeli} \mathrm{tarafından} \mathrm{tespit}$ edilememiştir. $\mathrm{Bu}$ senaryonun başarısı da \%100 olarak bulunmuştur. Arka plan ve maket ev nesnelerinde oluşturulan gürülttüye rağmen, bitki nesnesi olarak tanınmamışlardır. Mobil robotun senaryo yolunda ev nesneleri tanımasına ilişkin tablo Tablo 2' de verilmiştir. 
Tablo 2: Mobil robotun senaryo yolundaki ev nesnelerini tanıma başarı tablosu.

\begin{tabular}{l|c|c|c|c}
\hline Test-2 & Ev-1 & Ev-2 & Yeşil Ev-3 & Ev-4 \\
\hline Soldan-Să̆a & $\mathbf{x}$ & $\mathbf{x}$ & $\mathbf{x}$ & $\mathbf{x}$ \\
\hline Să̆dan-Sola & $\mathbf{x}$ & $\mathbf{x}$ & $\mathbf{x}$ & $\mathbf{x}$ \\
\hline Soldan-Să̆a & $\mathbf{x}$ & $\mathbf{x}$ & $\mathbf{x}$ & $\mathbf{x}$ \\
\hline
\end{tabular}

Sınamanın üçüncü senaryosunda, maket evler ve bitki nesneleri senaryo yoluna maket ev, bitki nesnesi, maket ev ve bitki nesnesi sırasıyla yerleştirilmiştir. Her nesne 3 metrelik senaryo yolu üzerinde eşit aralıklarla sıralanmışıtır. Üçüncü sınama senaryo yolunun sol uç kısmından başlatılmıştır. Maket evlerin hiçbiri bitki nesnesi olarak tanınmazken, bitki nesnelerinin hepsi de doğru olarak tanınmıştır. Maket ev bulunduran aşamalarda mobil robotun nesnelere uzaklığı yaklaşık 85 ile 90 santim arasınđadır. Çünkü maket evlerin boyu bitki nesnelerinin boyundan biraz daha kısa olmasından kaynaklanmaktadır (sadece bitki nesneleri olan senaryolarda uzaklık 75-85 santim arasında uygulanmıştır). Mesafe artırılarak maket evlerin büyük bir kısmınıın kameranın görüş açısına girdirilmesi hedeflenmiştir (gerçek uygulamada robotun nesnelere olan uzaklığının algoritmik olarak uyaflanmasının, böylece kamera görüntüsünün iyi bir konumdan alınması üzerinde çalışılmalıdır). Bu senaryonun başarısı da \%100 olarak bulunmuştur. Mobil robotun senaryo yolunda ev ve bitki nesnelerini tanımasına ilişkin tablo Tablo 3' de verilmiştir.

Dördüncü senaryoda ise maket ev ve bitki nesneleri çok yakın mesafelere yerleştirilmişlerdir. Maket ev ve bitki nesneleri aynı yatay doğrultuda ve cisimlerin ağırlık merkezleri yaklaşık olarak kesişmektedir. Yani bir nesne diğerinden daha ileride veya geride konumlanmamıştır. Maket evlerin hiçbiri bitki nesnesi olarak tanınmazken, bitki nesnelerinin hepsi de doğru olarak tanınmıştır. Senaryo tamamlandığında elde edilen sonuç, kadraja giren her iki nesneden sadece bitkinin tanınmasıyla sonuçlanmıştır. Bu senaryonun başarısı da \%100 olarak bulunmuştur. Mobil robotun senaryo yolunda ev ve bitki nesnelerini tanımasına ilişkin tablo Tablo 4' de verilmiştir.

Tablo 3: Mobil robotun senaryo yolundaki ev ve bitki nesnelerini tantma başarı tablosu.

\begin{tabular}{l|c|c|c|c}
\hline Test-3 & Ev-1 & Bitki-1 & Ev-2 (Yeşil) & Bitki-2 \\
\hline Soldan-Să̆a & $\mathbf{x}$ & $\boldsymbol{x}$ & $\mathbf{x}$ & $\boldsymbol{V}$ \\
\hline Săgdan-Sola & $\mathbf{x}$ & $\boldsymbol{V}$ & $\mathbf{x}$ & $\boldsymbol{V}$ \\
\hline Soldan-Să̆a & $\mathbf{x}$ & $\boldsymbol{V}$ & \\
\hline
\end{tabular}

Tablo 4: Mobil robotun senaryo yolundaki maket ev ve bitki nesnesinin çok yakın olduğu durumda nesneleri tanıma başarısı.

\begin{tabular}{|c|c|c|c|}
\hline Test-4 & \begin{tabular}{|l|l} 
Ev-Bitki İkilisi-1 & Ev-Bitki İkilisi-2 \\
\end{tabular} & Ev(Yeşil)-Bitki İkilisi-3 & Ev-Bitki İkilisi-4 \\
\hline Soldan-Să̆a & Ev: $\boldsymbol{X}$ Bitki: & Ev: $\boldsymbol{X}$ Bitki: $\boldsymbol{V}$ & Ev: $\boldsymbol{X}$ Bitki: $\mathscr{V}$ \\
\hline Sağdan-Sola & Ev: $\boldsymbol{X}$ Bitki: $\boldsymbol{V} \quad$ Ev: $\boldsymbol{X}_{\text {Bitki: }}$ & Ev: $\mathbf{X}$ Bitki: $\mathscr{V}$ & Ev: X Bitki: \\
\hline Soldan-Să̆a & Ev: $\boldsymbol{X}$ Bitki: $\boldsymbol{O}$ Ev: $\boldsymbol{X}$ Bitki: $\mathscr{V}$ & Ev: $\boldsymbol{X}$ Bitki: $\boldsymbol{V}$ & Ev: $\boldsymbol{X}$ Bitki: $\boldsymbol{V}$ \\
\hline
\end{tabular}

Beşinci senaryo ise, bir önceki aşamadan farklı olarak maket ev ve bitki nesnelerinin iç içe geçmiş hallerinden (kesiştikleri) oluşturulmuştur. Maket ev ile bitki nesnelerinin iç içe geçmesi nesne tanıma başarısını etkilemezken, düşük seviyede aydınlatma bölgesi olarak kullanılan senaryo yolunun bitiminde bulunan bölgede doğru nesne tanıma oranı \%33 olarak bulunmuştur. Nesnelerin içiçe geçtiği bölgelerde ise kamera görüntüsüne bağlı olarak (kısmi nesne parçası içerildiğinden) birden fazla bitki tanıması yapılmıştır. Bu senaryonun genel başarı oranı bitki nesneleri bazında \%83 olarak bulunmuştur. Mobil robotun senaryo yolunda ev ve bitki nesnelerini tanımasına ilişskin tablo Tablo 5' de verilmiştir.

Bu senaryolar sonunda elde edilen ilk bulgu, eğer iki nesne yanyana yer alıyor iseler, alınan kamera görüntüsü içinde diğer nesnenin parçasının bulunmasından dolayı tanıma işlemi iki kere gerçekleşebilmektedir. Bu durum esasında eğer bitki boyutları büyük ise, bitkinin kamera görüntüsü içinde kaldığı her frame için sulama veya ilaçlama eylemi yapılacaktır. Bu da tanıma problemi değil, işin doğası gereği olması gereken bir durum olarak algılanmalıdır. İkinci bulgu ise, nesnenin bulunduğu konumdaki aydınlatma diğer bölgelere göre daha az ise, bu durum tanınma başarısını etkilemektedir. Az 1şıklandırma nesnenin, farklı nesneler gibi görünmesine yol açmakta, karmaşık yapıdaki nesneler için VJ algoritmasının nesneyi yanlış tanımasına ya da hiç tanımamasına sebep olmaktadır.

Tablo 5: Mobil robotun senaryo yolundaki içiçe geçmiş maket ev ve bitki nesnelerini tanıma başarısı.

\begin{tabular}{|c|c|c|c|c|}
\hline Test-5 & Ev-Bitki İkilisi-1 & Ev(Yeşil)-Bitki İkilisi-1 & Ev-Bitki İkilisi-1 & Ev-Bitki İkilisi-1 \\
\hline Soldan-Să̆a & Ev: $\mathbf{X}$ Bitki: $\boldsymbol{V}$ & Ev: $\boldsymbol{X}$ Bitki: $\boldsymbol{V}$ & Ev: $\mathbf{X}$ Bitki: $\boldsymbol{V}$ & - \\
\hline Să̆dan-Sola & Ev: X Bitki: & Ev: $X$ Bitki: $\mathscr{V}$ & Ev: X Bitki: $/$ & Ev: $\boldsymbol{X}$ Bitki: $\boldsymbol{V}$ \\
\hline Soldan-Sağa & Ev: X Bitki: $\mathcal{V}$ & Ev: X Bitki: $\boldsymbol{V}$ & Ev: X Bitki: $\boldsymbol{V}$ & - \\
\hline
\end{tabular}


VJ algoritması göz önünde bulundurulduğunda, bitki nesnelerini içeren fotoğraflardan alınan örneklerin içeriği, görüntü kalitesi, 1şıklandırmanın yönü ve nesnenin karmaşıklık yapısından doğrudan etkilenmektedir. Görüntü kalitesi düşük olan fotoğraflardan elde edilen pozitif örnekler eğitimin doğruluğunu negatif yönde etkilemektedir. Buna ek olarak ilgili nesnelerden alınan pozitif örneklerin ilgili nesnelerin iç ya da dış bölgesinden alınan örneklerine göre yapılan eğitimlerin sonuçları farklı olmaktadır. Bu nedenle ilgili nesnelerin detaylara sahip bölgelerinden elde edilen pozitif örnekler, VJ algoritmasını başarımını artırmaktadır. Bu çalışma ile ayrıca, gerekli koşullar sağlandığında VJ nesne tanıma algoritmasının içeriği karmaşık olan nesneleri başarı ile tanıyabildiği gösterilmiştir. Ortamda benzer içeriklere sahip nesnelerin gürültülerini gidermek amacıyla VJ framelerinin sayısı Min Neighbors algoritması yöntemiyle sınırlandırılabilir. Çoğu nesne için 3 ile 7 arasında bir frame komşuluk değeri yeterlidir. Çalışmada en yakın komşuluk değeri 6 olarak belirlendiğinde en iyi sınama sonuçları elde edilmiştir.

Yapılan sınamalarda, $5 * 12=60$ nesnenin 58 tanesi doğru tespit edilmiştir, bu mobil sulama/ilaçlama robotunun görme yetisi ve bitki nesnelerini tanıma başarısının yaklaşık olarak \%96.5 gibi oldukça yüksek bir düzeye çıkarıldığını göstermektedir. Bundan sonra yapılacak çalı̧̧ma, robotun arazi ortamına adapte edilerek, karşılaşlabilecek görsel sorunlara (bazılarını açıkladık) çözüm üreterek, modeli faydalı bir ürün haline getirmektir.

\section{Kaynakça}

[1] Liu Yun, Zhang Peng, An Automatic Hand Gesture Recognition System Based on Viola-Jones Method and SVMs, 2009 Second International Workshop on Computer Science and Engineering, pp. 72-75.

[2] Ramana Isukapalli, Ahmed Elgammal, Russell Greiner (2006): Learning to detect objects of many classes using binary classifiers. 9th European Conference on Computer Vision (ECCV 2006). Vol. 3951, no.1, pp. 352-364.

[3] Mohammad Mahdi M., Maryam N., Majid P. and Mohammad Kazem M. (2018): Moving Véhicle Detection Using AdaBoost and Haar-Like Feature in Surveillance Videos. International Journal of Imaging and Robotics. Vol. 18, po. 1.

[4] Moad. Benkiniouar, Mohamed Benmohammed (2010): Optimisation the real time implementation of the Viola \& Jones face detection algorithm on RIse processor. 2010 XIth International Workshop on Symbolic and Numerical Methods, Modeling and Applications to Circuit Design (SM2ACD). IEEE.

[5] Yasaman Heydarzadeh, Abolfazl Toroghi Haghighat, Nazila Fazeli (2010): Utilizing Skin Mask and Face Organs Detection for Improving the Viola Face Detection Method. 2010 Fourth UKSim European Symposium on Computer Modeling and Simulation. Pp. 174-178, IEEE.

[6] Rapee Krerngkamjornkit, Milan Simic (2013): Enhancement of human body detection and tracking algorithm based on Viola and Jones framework. 2013 11th International Conference on Telecommunications in Modern Satellite, Cable and Broadcasting Services (TELSIKS). Vol. 1, pp. 115-118, IEEE.

[7] Dewiani Djamaluddin, Tantri Indrabulan, Andani, Indrabayu, Sitti Wetenriajeng Sidehabi (2014): The Simulation of Vehicle Counting System for Traffic Surveillanee Using Viola Jones Method. 2014 Makassar International Conference on Electrical Engineering and Informatics (MICEEI).pp. 130-135, IEEE.

[8] Yongzheng Xu, Guizhen Yu, Member, IEEE, Xinkai Wu, Yunpeng Wang, and Yalong Ma (2017): An Enhanced Viola-Jones Vehicle Detection Method FromUnmanned Aerial Vehicles Imagery. IEEE Transactions on Intelligent Transportation Systems. Vol. 18, no. 7, pp. 1845-1856. IEEE.

[9] Muhammad R Wiratama, Sukmawati N Endah, Retno Kusumaningrum, Helmie A Wibawa (2017): Pornography Object Detection Using Viola-Jones Algorithm and Skin Detection. 2017 1st International Conference on Informatics and Computational Sciences (ICICoS). P. 29-34. IEEE.

[10] Kartika Candra Kirana, Slamet Wibawanto, Heru Wahyu Herwanto (2018): Facial Emotion Recognition Based on Viola-Jones Algorithm in the Learning Environment. 2018 International Seminar on Application for Technology of Information and Communication (iSemantic). Pp. 406-410. IEEE.

[11] Pooya Tavallali, Mehran Yazdi, Mohammad Reza Khosravi (2017): An Efficient Training Procedure for Viola-Jones Face Detector. 2017 International Conference on Computational Science and Computational Intelligence (CSCI). Pp. 828-831. IEEE.

[12] Benny Hardjono, Hendra Tjahyadi, Mario G. A. Rhizma, Andree E. Widjaja, Roberto Kondorura, Andrew M. Halim (2018): Vehicle Counting Quantitative Comparison Using Background Subtraction, Viola Jones and Deep Learning Methods. 2018 IEEE 9 th Annual Information Technology, Electronics and Mobile Communication Conference (IEMCON). Pp. 556-562. IEEE.

[13] LU Wen-yaoYang Ming (2019): Face Detection Based on Viola-Jones Algorithm Applying Composite Features. 2019 International Conference on Robots \& Intelligent System (ICRIS). Pp. 82-85. IEEE.

[14] Paul Viola Michael Jones (2001): Rapid Object Detection using a Boosted Cascade of Simple Features. Proceedings of the 2001 IEEE Computer Society Conference on Computer Vision and Pattern Recognition. CVPR 2001. Pp. 511-518. IEEE.

[15] Haluk Özgen, Metin Turan (2018): Camera Assisted Mobile Medication and Irrigation Robot Design. ELECO 2018, ElektrikElektronik ve Biyomedikal Mühendisliği Konferansı. Pp. 162-168. 